CASE NOTES

\title{
SYMPATHETIC OPHTHALMIA FOLLOWING AN OPERATION FOR RETINAL DETACHMENT*
}

\author{
BY \\ WALTER KORNBLUETH AND RICHARD STEIN \\ Ophthalmological Department, Rothschild Hadassah University Hospital, Jerusalem, \\ and Tel Hashomer General Hospital, Israel
}

THIS report seems justified since no mention is made in the textbooks of ophthalmology and ophthalmic pathology of sympathetic ophthalmia following an operation for retinal detachment. 'Friedenwald and others (1952) state:

Sympathetic ophthalmia has not as yet been reported following operations for detachment of the retina.

Duke-Elder (1940) does not include the operation for retinal detachment in the long list of those sometimes followed by sympathetic ophthalmia.

\section{Case Report}

A boy, aged $8 \frac{1}{2}$ years, was admitted to the Hadassah University Hospital with detachment of the retina in the right eye.

The family history revealed that the patient's father, his paternal grandmother, and his grandfather had had high myopia. Three of his grandmother's brothers had suffered from retinal detachment. At the age of $3 \frac{1}{2}$, tonsillectomy had been performed because of recurring angina, and he had had measles at the age of 6 .

November 28, 1945, when $3 \frac{1}{2}$ years old, he was examined by Professor Feigenbaum who found excessive myopia (over 17 dioptres) and prescribed -15 D. for each eye.

September, 1950, he was seen again and complained of deterioration of vision in the right eye. Externally, the eyes did not show anything abnormal. Visual acuity was perception of light in the right eye, which had in the meantime received for correction $-29 \mathrm{D}$. sph., and in the left eye it was 5/12 partly with correction-24 D. sph, comb. -1 cyl. Ophthalmoscopy of the right eye revealed an almost total detachment of the retina with large tears near the ora serrata at the lower temporal quadrant; the left eye showed extensive vitreous opacities and fundus changes typical of excessive myopia.

September 18, 1950, the right eye was operated on for retinal detachment. The lower bulbar conjunctiva was freed from 3 o'clock-10 o'clock and surface cautery applied to the sclera in this area at a distance of 6-13 mm. from the limbus. From 6.30-8.30 o'clock, at a distance of 8-10 $\mathrm{mm}$. from the limbus, two rows of penetrating punctures were carried out with $1 \frac{1}{2}-\mathrm{mm}$. Safar needles. A large quantity of subretinal fluid was evacuated. At the end of the operation, the retina was fairly well re-attached.

After the operation, the patient was very unruly and could not be kept quietly in bed.

September 24, 1950, vision in the operated right eye was counting fingers at $3 / 4 \mathrm{~m}$. The visual field was constricted from above and on ophthalmoscopy the lower half of the retina appeared to be detached.

October 11, 1950, the patient left the hospital, and the detachment of the retina became complete. Visual acuity amounted to recognition of hand movements in front of the eye.

* Received for publication June 11, 1953. 
December 25, 1950, externally, the right eye was slightly injected, the cornea clear, there was a hyphaema of $3 \mathrm{~mm}$. and the iris was slightly discoloured. The lens was transparent and the vitreous filled with blood. The left eye showed no changes other than those described above.

March, 1951, the hyphaema in the right eye had disappeared but seclusion of the pupil had developed. The eyeball was very soft and had begun to shrink. Enucleation was advised but was refused by the parents.

June 17, 1951, the boy complained of severe pains in the right eye, and ran a high temperature. External examination of the right eye showed oedema of the lids, chemosis, slight haziness of the cornea, some fine keratic precipitates, and hyperaemia of the iris. The ocular tension was $56 \mathrm{~mm}$. Hg Schiötz. During the next few days, the inflammatory symptoms increased, and exophthalmos, due to orbital cellulitis, developed. A diagnosis of endophthalmitis was made. On treatment with streptomycin and penicillin, applied generally as well as locally, the acute inflammatory symptoms subsided after a fortnight.

July 7, 1951, fine keratic precipitates were noticed for the first time in the left eye. The right eyeball was enucleated immediately. In spite of local and general treatment with cortisone ( $3 \mathrm{~g}$.), the keratic precipitates in the left eye increased in size and number, nodules appeared in the iris, and posterior synechiae developed.

August 21, 1951, the retina became detached. During the following weeks the cornea was invaded by deep vessels, and seclusion and occlusion of the pupil appeared, accompanied later by a complicated cataract. Vision deteriorated to light perception with faulty projection, and eventually phthisis bulbi developed.

\section{Pathological Examination}

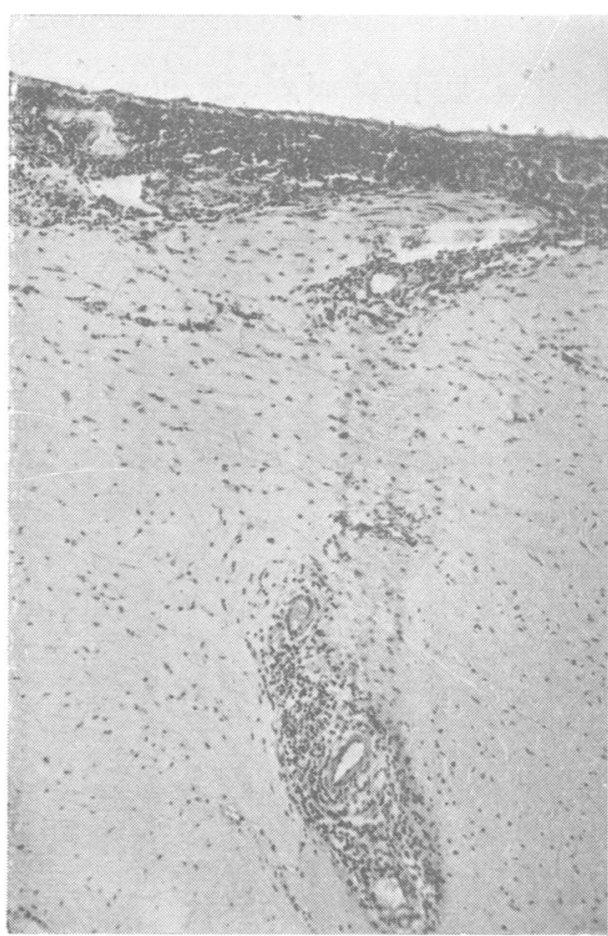

Fig. 1.-Diffuse infiltration of choroid with Inflammatory cells, spreading along ciliary vessels. Haemotoxylin and eosin. $\times 85$.
The dimensions of the enucleated right eyeball are $25 \times 20 \mathrm{~mm}$. The cornea, which is of normal thickness, shows some round cell infiltration near the limbus and invasion of blood vessels into the superficial and deeper layers. Precipitates, consisting mostly of lymphocytes with some pigment around them, are to be seen scattered on the corneal endothelium. The anterior chamber is filled with serum and some old blood. The iris shows anterior peripheral synechiae on both sides, and is oedematous, with dilation of the blood vessels and infiltration by lymphocytes and plasma cells. There are posterior synechiae and an inflammatory membrane is stretched over the anterior surface of the lens, which shows posterior cortical cataract. The ciliary body is heavily infiltrated with round cells and presents severe destruction of the pigment epithelium. There is a cyclitic membrane which is also infiltrated with round cells. The choroid shows heavy accumulation of round cells and some eosinophils which 


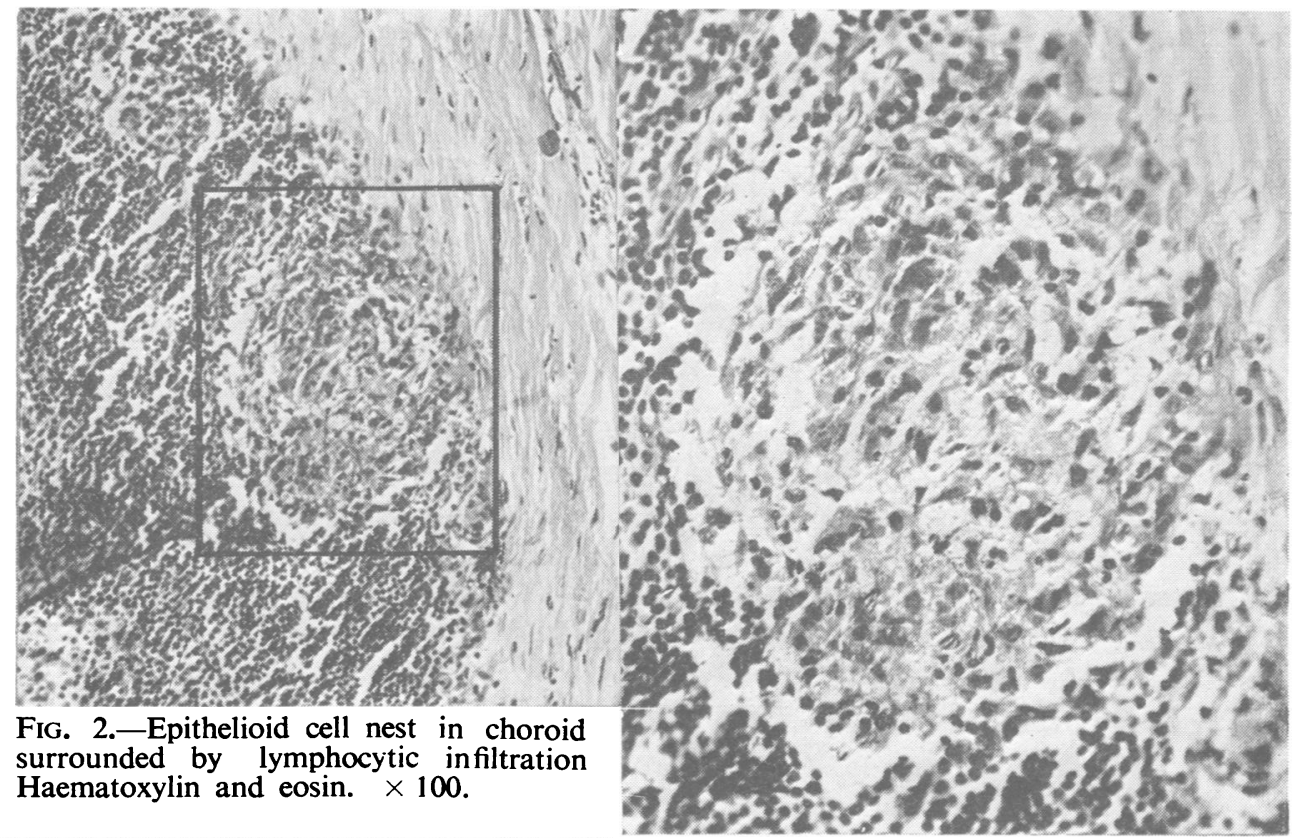

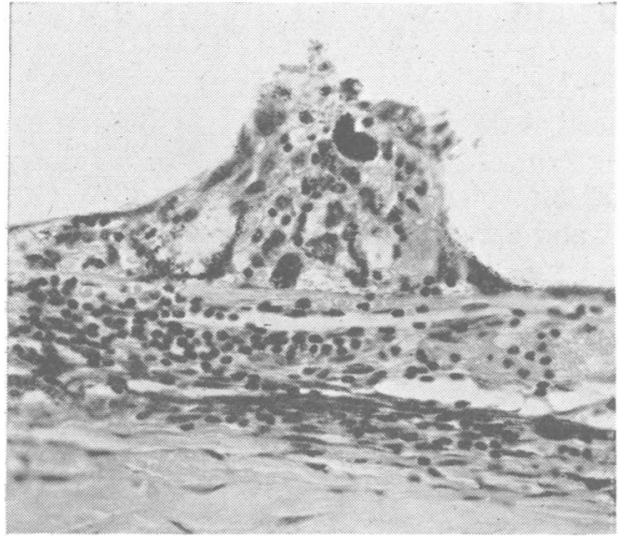

Fig. 4.-Dalen-Fuchs nodule. Haematoxylin and eosin. $\times 260$.
FIG. 3.-Epithelioid cells containing fine melanin granules. Enlargement of frame marked in Fig. 2. Haematoxylin and eosin. $\times 240$.

also spread along the ciliary vessels and nerves (Fig. 1). In a few areas, nests of epithelioid cells containing phagocytosed uveal pigment granules are to be seen (Figs 2 and 3). Near the ora serrata, the pigment epithelium shows some small nodules which consist of pigment epithelium cells and epithelioid cells containing phagocytized pigment granules-Dalen-Fuchs nodules (Fig. 4). The retina is completely detached and atrophic. There is a massive intraocular haemorrhage. Diagnosis: sympathetic ophthalmia. ${ }^{*}$

\section{Summary}

A case of sympathetic ophthalmia following an operation for retinal detachment in an $8 \frac{1}{2}$-year-old boy is described. The sympathogenic eye was enucleated and in spite of energetic treatment with cortisone the sympathizing eye became phthisic.

\section{REFERENCES}

Duke-Elder, S. (1940) “Text-book of Ophthalmology”, vol. 3, p. 2328. Kimpton, London. Friedenwald, J. S., Wilder, H. C., Maumenee, A. E., Sanders, T. E., Keyes, J. E. L., Hogan, M. J., OWEns, E. U., AND Owens, W. C. (1952). " Ophthalmic Pathology. An Atlas and Textbook", p. 127. Saunders, Philadelphia. 